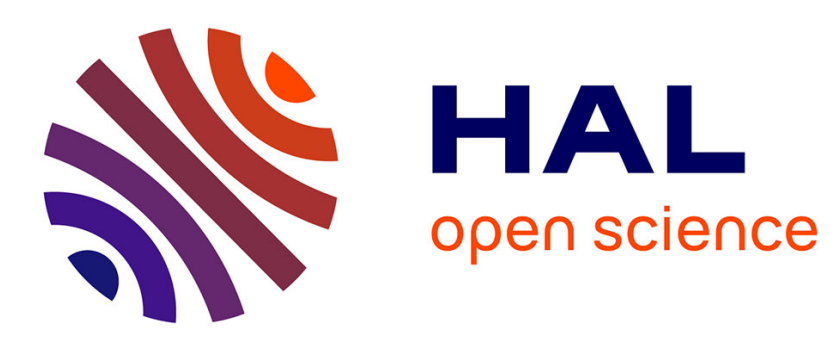

\title{
Estimating the Competitive Storage Model with Trending Commodity Prices
}

\author{
Christophe Gouel, Nicolas Legrand
}

\section{To cite this version:}

Christophe Gouel, Nicolas Legrand. Estimating the Competitive Storage Model with Trending Commodity Prices. Journal of Applied Econometrics, 2017, 32 (4), pp.744-763. 10.1002/jae.2553 . hal01584507

\section{HAL Id: hal-01584507 \\ https://hal.science/hal-01584507}

Submitted on 18 Sep 2017

HAL is a multi-disciplinary open access archive for the deposit and dissemination of scientific research documents, whether they are published or not. The documents may come from teaching and research institutions in France or abroad, or from public or private research centers.
L'archive ouverte pluridisciplinaire HAL, est destinée au dépôt et à la diffusion de documents scientifiques de niveau recherche, publiés ou non, émanant des établissements d'enseignement et de recherche français ou étrangers, des laboratoires publics ou privés. 


\title{
Estimating the Competitive Storage Model with Trending Commodity Prices*
}

\author{
Christophe Gouel ${ }^{\dagger 1,2} \quad$ Nicolas Legrand ${ }^{\ddagger 1,3}$ \\ ${ }^{1}$ Économie Publique, AgroParisTech, INRA, Université Paris-Saclay, 78850, Thiverval-Grignon, France \\ ${ }^{2}$ CEPII, 113 rue de Grenelle, 75007, Paris, France \\ ${ }^{3}$ Climate Economics Chair, Palais Brongniart, 28 Place de la Bourse, 75002, Paris, France
}

\begin{abstract}
We present a method to estimate jointly the parameters of a standard commodity storage model and the parameters characterizing the trend in commodity prices. This procedure allows the influence of a possible trend to be removed without restricting the model specification, and allows model and trend selection based on statistical criteria. The trend is modeled deterministically using linear or cubic spline functions of time. The results show that storage models with trend are always preferred to models without trend. They yield more plausible estimates of the structural parameters, with storage costs and demand elasticities that are more consistent with the literature. They imply occasional stockouts, whereas without trend the estimated models predict no stockouts over the sample period for most commodities. Moreover, accounting for a trend in the estimation imply price moments closer to those observed in commodity prices. Our results support the empirical relevance of the speculative storage model, and show that storage model estimations should not neglect the possibility of long-run price trends.
\end{abstract}

Keywords: Commodity prices, non-linear dynamic models, storage, structural estimation, trend.

JEL classification: C51, C52, Q11.

\footnotetext{
*This is the peer reviewed version of the following article: "Gouel, C. and N. Legrand (2017). Estimating the Competitive Storage Model with Trending Commodity Prices. Journal of Applied Econometrics, 32(4), 744-763", which has been published in final form at http://doi .org/10.1002/jae.2553. This article may be used for non-commercial purposes in accordance with Wiley Terms and Conditions for Self-Archiving.

We would like to thank the editor Thierry Magnac and two anonymous referees, as well as Alain Ayong le Kama, Stephane De Cara, Christophe Muller, Fabien Tripier, and James Vercammen for their helpful suggestions. We are grateful to Carlo Cafiero for sending us its estimation code. This research was generously supported by the European Union's Seventh Framework Programme FP7/2007-2011 under Grant Agreements no 290693 FOODSECURE and by Total - Scientific Division. The authors only are responsible for any omissions or deficiencies. The European Union and European Commission are not accountable for the content of the paper.

†christophe.gouel@inra.fr

$\ddagger$ nicolas.legrand@inra.fr
} 


\section{Introduction}

Gustafson's (1958) commodity storage model is fundamental for explaining the annual behavior of commodity prices. It features forward-looking speculators that maximize profit by stockpiling a commodity based on the difference between the expected price and the current price. The source of volatility in the commodity storage model is the occurrence of unexpected supply shocks. The model has proven capable of reproducing many features of commodity prices such as sharp spikes, volatility clustering, positive skewness, and excess kurtosis (Deaton and Laroque, 1992). However, in early estimations of this model, Deaton and Laroque $(1992,1996)$ show that it could not explain the high degree of serial correlation observed in the price series. This finding was challenged. Cafiero et al. (2011b) show that using a finer grid to approximate the policy function and a different model specification, the storage model is able to generate the observed serial correlation for seven of the twelve commodities analyzed in Deaton and Laroque (1996). Since Cafiero et al. (2011b), several papers provide positive evidence for the role of storage arbitrage in price behavior (Bobenrieth et al., 2013, 2014; Cafiero et al., 2015; Guerra et al., 2015). However, if the model is estimated on untransformed real price indexes (as in Cafiero et al., 2011b), discretionary stocks are always strictly positive (i.e., there are no "stockouts") for most commodities over the sample interval. This result casts doubt on the appropriateness of using for estimation a nonlinear model with two regimes (with and without stocks) if, over long samples and for most commodities, the estimations imply that only one regime is active.

The absence of predicted stockouts in the sample indicates a possible model misspecification. This misspecification may arise from the attempt to fit with the storage model a serial correlation that is artificially high, due to a possible non-stationarity in the price series. Commodity prices are unlikely to be stationary over long periods. Starting with the work by Prebisch (1950) and Singer (1950), a large literature has been devoted to characterizing the nature of this non-stationarity: whether trends are stochastic or deterministic, the existence of long-run cycles, or secular decline of commodity prices relative to those of manufactures (e.g., Grilli and Yang, 1988; Cashin and McDermott, 2002; Ghoshray, 2011; Harvey et al., 2010). As illustrated in figure 1, the nature of the trends (or their absence) tends to be specific to each commodity (e.g., mostly trendless behavior after a decreasing interval for copper, hump-shape behavior for cotton, monotonically decreasing for rice). Removing the trends using an Hodrick-Prescott filter reduces the one-year autocorrelation in commodity prices by one-third from about 0.85 to 0.5 (see table A3 in the online appendix). We show below in the article that to generate with the storage model an autocorrelation in prices as high as 0.85 requires extreme parameter values, corresponding to very low storage costs along with very inelastic demand thereby implying extremely rare stockouts, while a smaller autocorrelation is compatible with more plausible parameters and occasional stockouts. Low storage costs are needed to match a high autocorrelation because they ensure there are always stocks to connect one period to the next. So estimating the storage model, which features prices converging to a stationary distribution, with untransformed prices (as in Deaton and Laroque, 1992, 1996; Cafiero et al., 2011b) is likely to lead to biased parameter estimates if prices are non-stationary. The present article assesses the role of potential non-stationary price series in estimations of the storage model, and proposes an approach that statistically accounts for a trend in the price series.

How to estimate dynamic stochastic rational expectations models that are defined to be stationary around a steady state using non-stationary data is a very important question in the related literature on the estimation of DSGE models. In a recent paper, Canova (2014) summarizes the various strategies used in this literature. Most apply also to the storage model. Most DSGE models are estimated on transformed data in two steps. First, a statistical filter (linear detrending, first-order differencing, 


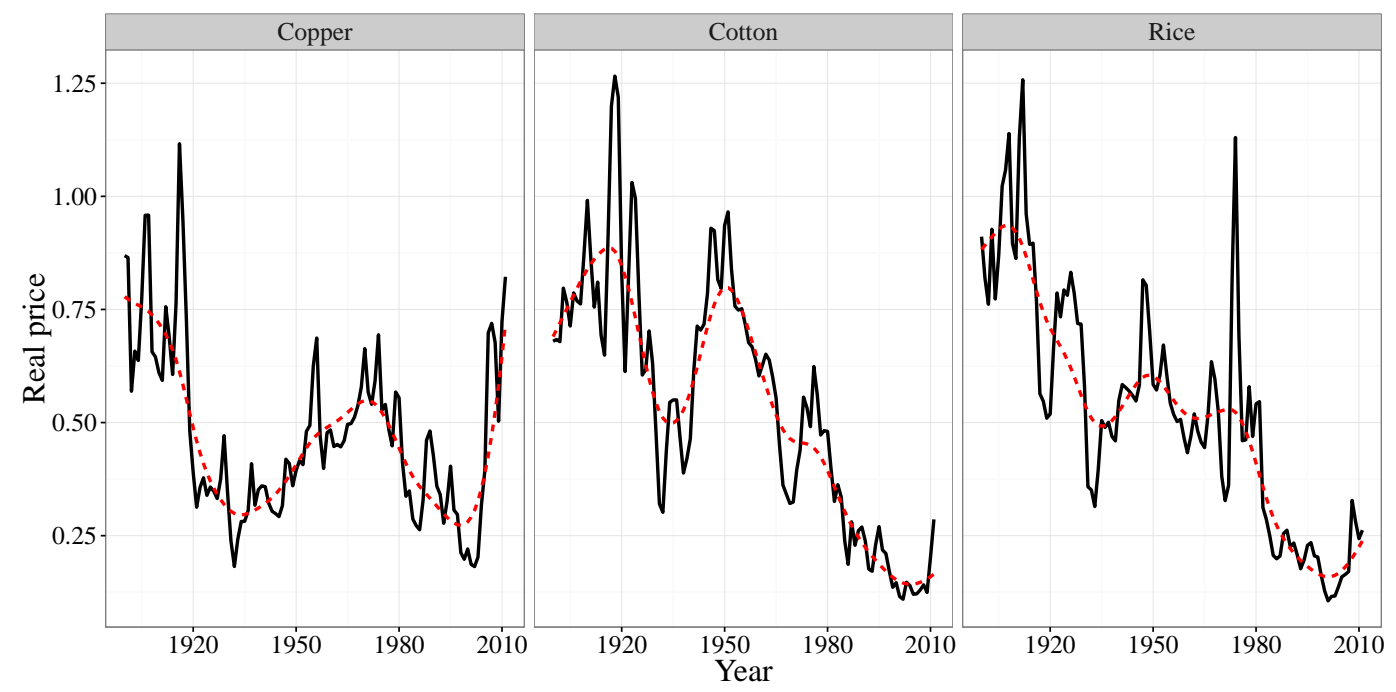

Figure 1: Real prices and Hodrick-Prescott trend (smoothing parameter 400)

Hodrick-Prescott or band-pass filters) is applied to the raw data, then the structural model is estimated using the transformed data. This approach is convenient but is known to involve problems. The business cycle facts will depend on the choice of filter which is arbitrary (Harvey and Jaeger, 1993; Canova, 1998), due to lack of formal tests to select the most appropriate trend specification. For the storage model, the two-step approach is applied in Cafiero et al. (2011a), Bobenrieth et al. (2013), and Guerra et al. (2015) where prices are detrended ex-ante using a log-linear trend.

Another approach involves the construction of a model that includes transitory and permanent shocks, the latter aimed at capturing non-cyclical fluctuations. The model is made stationary by scaling the variables by the permanent shocks, and is fitted to the raw data. This approach has the appeal of theoretical consistency but introduces the risk of misspecification. Because it is not possible to make every model stationary for all possible specifications of permanent shocks, the model design and the nature of the shocks may be driven more by computational than economic motives. This approach is applied in Zeng (2012) and Bobenrieth et al. (2014) with storage models in which storers internalize the downward trend in commodity prices and adjust their behavior accordingly, and in Dvir and Rogoff (2014) where quantities are non-stationary, but not prices. However, to obtain stationary equations while accounting for a trend in prices, various restrictions must be satisfied: the trend must be multiplicative and the logarithm of the trend is restricted to take the form of a random walk with drift; the demand function has to be isoelastic, but not linear as commonly adopted for numerical simplicity; and storage costs must either be zero or have the same trend as prices.

Canova (2014) proposes an alternative method to estimate DSGE models using raw data. ${ }^{1}$ In this approach, the econometrician defines a statistical model which is a combination of a DSGE and a reduced-form model; the reduced-form is aimed at capturing the component in the data the structural model is unable to explain. This statistical model can be estimated using raw data, which leads to joint estimation of the structural and reduced-form parameters. Interestingly, this one-step approach allows to select the most likely trend specification based on a statistical criterion for model selection. Furthermore, it presents the benefit of not restricting the trend and model specifications, but

${ }^{1}$ See also Ferroni (2011) for an application. 
at the cost of the agents neglecting the trends in their decisions.

The choice between the approaches amounts to a trade-off between theory and empirics. If the conditions under which a storage model can be made stationary are too restrictive with respect to the prevailing trends, it may not be possible to properly capture them in the model. The most severe restriction for a storage model with trending prices is probably that the trend has to be the exponential of a random walk with drift, possibly collapsing to a simple linear trend if the random walk step has zero length. It is unlikely to be satisfied for most commodities. In the literature on long-run trends in commodity prices, a consensus has emerged (Kellard and Wohar, 2006; Balagtas and Holt, 2009; Harvey et al., 2010; Ghoshray, 2011; Cuddington and Nülle, 2014; Yamada and Yoon, 2014): (i) one can exclude a positive upward trend for commodity prices, (ii) there is no general support for the Prebisch-Singer hypothesis of a secular deterioration with respect to manufactured goods for all commodities, with most commodity prices actually better characterized by discontinuous, deterministic, and non-monotonic long-term trends, possibly negative over some intervals, and (iii) the remaining commodity prices displaying a unit root, possibly with breaks. In sum, if most commodities are found to be trend stationary, it is by segments divided by infrequent shifts. Since a random walk with drift would not be a satisfactory trend specification for most commodities, we adopt Canova's approach by jointly estimating a storage model and a reduced-form trend that describes the non-cyclical component of price. Our approach implies that the storers neglect the existence of a trend in prices and arbitrate prices only on the basis of their cyclical component. This issue is likely to be of second order compared to the gains from making the prices more stationary (as confirmed in Zeng, 2012, who finds little differences in estimations on small sample whether storers account for trend or not).

The estimation procedure starts from the Maximum Likelihood estimator proposed for the storage model by Cafiero et al. (2015), and which was proved to have better small sample properties than Deaton and Laroque's (1996) Pseudo-Maximum Likelihood estimator. We extend the Maximum Likelihood estimator to account for a potential trend in prices and to exploit the information available from the first observation. This leads to the development of a new simulated unconditional Maximum Likelihood estimator. Following the finding that most commodity prices are best characterized as trend stationary with breaks, we consider only deterministic trend specifications. This assumption simplifies the analysis by allowing the likelihood to be expressed analytically, ${ }^{2}$ at the cost of being inadequate for the commodity prices best characterized as difference stationary. As well as the case without trend, we consider a multiplicative trend, in which the logarithm of the trend can be linear as in Cafiero et al. (2011a), Bobenrieth et al. (2013, 2014), and Guerra et al. (2015), or represented by a restricted cubic spline as in Roberts and Schlenker (2013). We believe that by using for the trend a restricted cubic spline with up to four knots we are able to capture in a tractable way the deterministic trends with breaks identified in the literature. For the thirteen storable commodities considered in Deaton and Laroque (1992), there is a model with trend which presents a lower Akaike information criterion than the model without trend. Our estimates for the preferred models more closely replicate the key features of the data and allow for the occurrence of stockouts in line with the observed two-regime structure of long periods of stable prices interrupted by isolated spike episodes.

The remainder of the paper is organized as follows. Section 2 describes the competitive storage model discussed and estimated in Deaton and Laroque (1992, 1996) and Cafiero et al. (2011b). Section 3 presents the econometric procedure used to estimate the storage model with multiplicative deterministic trend, and describes how the unconditional maximum likelihood estimator is constructed. Section 4

\footnotetext{
${ }^{2}$ Stochastic trends would require a non-linear state-space approach and the use of particle filters (Fernández-Villaverde and Rubio-Ramírez, 2007), a promising but challenging approach for a model as non-linear as the storage model.
} 
presents the empirical results, and section 5 concludes.

\section{The model}

\subsection{Model equations}

We adopt the standard competitive storage model with no supply response, constant marginal storage cost, and no stock deterioration in line with Cafiero et al. (2011b). The exogenous supply is modeled by i.i.d. random production shocks $\epsilon_{t}$ following a normal distribution with mean $\mu$ and standard deviation $\sigma$ truncated at five standard deviations. The demand for commodities consists of a demand for current consumption $C_{t}$ associated with the inverse demand function $D^{-1}\left(C_{t}\right)=a+b C_{t}$, which is assumed to be linear with fixed parameters $a$ and $b<0$, and a speculative demand from competitive risk-neutral storers. Storers carry over $S_{t} \geq 0$ units of the commodity into the next period whenever they expect a positive return to storage over the interest and physical storage costs, and otherwise sell their past inventories. Assuming rational expectations and taking account of the non-negativity constraint on storage yields the following arbitrage condition:

$$
\beta \mathrm{E}_{t} P_{t+1}-P_{t}-k \leq 0,=0 \text { if } S_{t}>0,
$$

where $\beta=1 /(1+r)$ is the discount factor which is assumed to be fixed, $k \geq 0$ is the constant per unit physical cost of storage, $P_{t}$ is the price, and $\mathrm{E}_{t}$ is the expectation operator conditional on period $t$ information. In equilibrium, supply equals total demand such that

$$
A_{t}=S_{t}+D\left(P_{t}\right)
$$

where the amount on hand $A_{t}$ at time $t$ is the sum of the past inventories and the stochastic production $\epsilon_{t}$ written as

$$
A_{t} \equiv S_{t-1}+\epsilon_{t}
$$

with $A_{t} \in \mathbb{A} \equiv[-5 \sigma, \infty)$.

Combined with the market clearing condition, the arbitrage condition (1) leads to two regimes in the price dynamics:

$$
P_{t}=\max \left[\beta \mathrm{E}_{t} P_{t+1}-k, D^{-1}\left(A_{t}\right)\right] .
$$

The first regime holds when speculators stockpile expecting the future price to cover the purchasing and full carrying costs. The second regime defines the stockout situation with empty inventories, where the market price is determined only by the final demand for consumption and the amount on hand in the market.

For this problem, a stationary rational expectations equilibrium is a price function $\mathcal{P}: \mathbb{A} \rightarrow \mathbb{R}$ which describes price as a function of contemporaneous availability. From equation (4), this price function satisfies for all $A_{t}$

$$
\mathcal{P}\left(A_{t}\right)=\max \left[\beta \mathrm{E}_{t} \mathcal{P}\left(S_{t}+\epsilon_{t+1}\right)-k, D^{-1}\left(A_{t}\right)\right],
$$

where, from (2), $S_{t}$ is given by

$$
S_{t}=A_{t}-D\left(\mathcal{P}\left(A_{t}\right)\right) \text {. }
$$

Building on Deaton and Laroque (1992), Cafiero et al. (2011b) prove that for this model there is a 
unique stationary rational expectations equilibrium $\mathcal{P}$ in the class of continuous strictly decreasing functions. ${ }^{3}$ If we define $P^{*} \equiv \beta \mathrm{E} \mathcal{P}(\epsilon)-k$, the cutoff price for no storage, the price function has the following properties:

$$
\begin{aligned}
& \mathcal{P}(A)=D^{-1}(A), \text { for } A \leq D\left(P^{*}\right), \\
& \mathcal{P}(A)>D^{-1}(A), \text { for } A>D\left(P^{*}\right) .
\end{aligned}
$$

So $P^{*}$, which depends on the price function, defines the threshold between the two regimes. Prices above $P^{*}$ are too high to make storage profitable, while for prices below $P^{*}$ some stocks are carried over.

There is no closed-form solution for the equilibrium price function, which has to be approximated numerically. The numerical method follows the fixed-point approach proposed by Deaton and Laroque (1992) and is described in section A1 of the online appendix.

\subsection{How can storage generate high serial correlation?}

The debate over the empirical relevance of the storage model revolves around its ability to generate the high serial correlation observed in the data. Here, we explore the combination of parameters that allows the model to generate high serial correlation. Our storage model has six parameters, $\{a, b, k, r, \mu, \sigma\}$. In the remainder of this paper, we follow Deaton and Laroque (1996) and Cafiero et al. (2015) by fixing $r$ at $5 \%$. Deaton and Laroque (1996, Proposition 1) prove that it is not possible to identify separately the demand function and the distribution of supply shocks. So in this section, we set the mean and standard deviation of the harvest at 1 and $0.05 .{ }^{4}$ The mean price over the model asymptotic distribution is set to 1 , which implies $a+b=1$. Two degrees of freedom remain: storage cost and demand elasticity. We vary them to see how this affects the serial correlation. Given our assumptions, $k$ can be interpreted as the ratio of storage costs with respect to the mean price, and the demand elasticity calculated at the mean price is simply equal to $1 / b$.

To analyze the effect of storage cost on serial correlation, we set demand elasticity at -0.05 , corresponding to Roberts and Schlenker's (2013) best estimate of the elasticity of a caloric aggregate of the major crops. We vary storage costs between 0 and 20 percent of the mean price, and for every value of storage cost we solve and simulate the model. We calculate the first-order autocorrelation for 100,000 series of 100 periods on the asymptotic distribution. As noted by Cafiero et al. (2011b), simulating the storage model generates time series with very volatile moments when the series length is around the number of observable annual prices (close to one hundred years). Therefore, it is not sufficient to compare the serial correlation of observable price to the average simulated first-order autocorrelation, we need also to compare it to the quantiles of the distribution of simulated first-order autocorrelation. The left panel of figure 2 displays the 5th, 50th, and 95th percentiles of the distribution of simulated first-order autocorrelation when we vary the storage cost. Serial correlation is a monotonically decreasing function of storage cost. This can be explained by the fact that the storage model displays two regimes. In one regime, there are positive stocks and prices are serially correlated. In the other, stocks are zero and prices are not serially correlated. The more time that is spent in the stockout regime, the lower will be the overall serial correlation generated by the model. Decreasing the storage cost makes storage more

${ }^{3}$ Cafiero et al. (2015) extend the proof to a model with free disposal and with a production support that may be unbounded. Free disposal has the advantage to prevent the realization of negative equilibrium prices, but increases significantly the time required to solve the model numerically preventing us from implementing it in this paper.

${ }^{4} \mathrm{~A}$ coefficient of variation of $5 \%$ for supply shocks is close to what is observed for the commodities considered in this paper (see table A5 in the online appendix). 
profitable, increases stock levels, thereby decreasing the likelihood of a stockout and increasing the serial correlation. With this calibration, even for a zero storage cost, the median first-order autocorrelation is well below the very high correlation observed in the price series (above 0.82 for all commodities except sugar). Even the 95th percentile is below 0.8 .

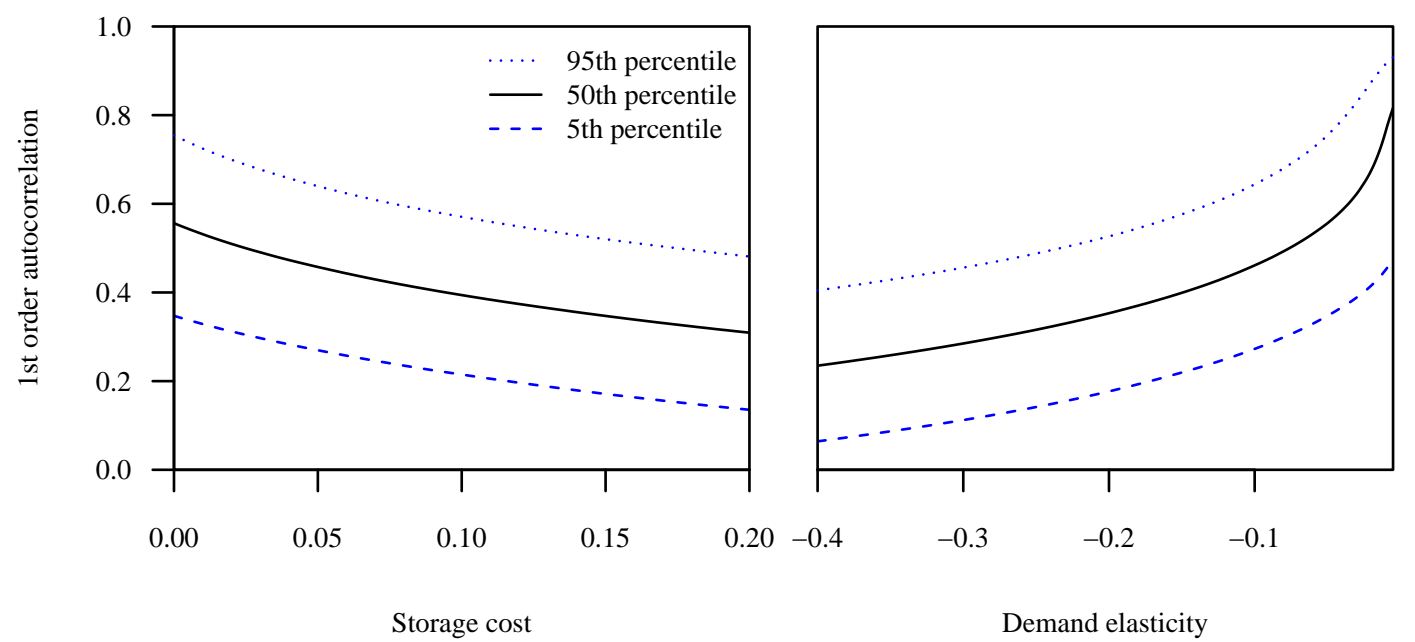

Figure 2: First-order autocorrelation implied by the storage model over 100 periods for several values of storage cost (with demand elasticity set at -0.05) and demand elasticity (with storage cost set at 0 )

This failure of the storage model to induce sufficient serial correlation in prices calls for a parameterization that is even more favorable to storage. This can be achieved by rotating the slope of the demand function around its mean. Indeed, in absence of inventories to buffer against short supply, the price adjustments are dictated only by the final demand for consumption. So the more inelastic the demand, the steeper the variations in prices and the greater the incentive to store. We set the storage cost at its zero lower bound and vary the demand elasticity between -0.4 and -0.005 (right panel of figure 2). Only for a very inelastic demand curve is the median of simulated first-order autocorrelation close to 0.8 . The 95 th percentile can be compatible with a first-order autocorrelation of 0.8 for a demand elasticity above -0.037 .

In the storage model with i.i.d. supply shocks, stockpiling is the sole source of time-dependency in prices, so only a model parameterization in which storage arbitrage is often active can generate high serial correlations. The model can generate high serial correlation only by decreasing the occurrence of stockouts which requires a parameterization of very low storage cost and very inelastic demand. So in the estimations that follow, we should expect that a storage model able to replicate the characteristics of the raw price series will be characterized by low storage costs and inelastic demand functions. Even with this combination, high first-order autocorrelation is achieved only by the high percentiles of the asymptotic distribution.

\section{Econometric procedure}

In this section, following Canova (2014), we propose an econometric procedure to estimate the storage model and the trend in prices jointly. The idea behind this procedure is to capture in the trend the component of prices that cannot be accounted for by the storage model, in particular the 
non-cyclical fluctuations. As a result, the storage model has to account only for cyclical fluctuations in the observed data. We assume that observed prices, $P_{t}^{\text {obs }}$, can be decomposed into a multiplicative trend $\exp \left[\Gamma\left(t, \theta^{\Gamma}\right)\right]$ and a cyclical component denoted $P_{t}^{\text {sto }}$ to be explained by the storage model:

$$
P_{t}^{\mathrm{obs}}=\mathrm{e}^{\Gamma\left(t, \theta^{\Gamma}\right)} P_{t}^{\mathrm{sto}} .
$$

The vector of the parameters to be estimated $\theta$ can be split into two groups: the trend parameters $\theta^{\Gamma}$, and the structural parameters of the storage model, $\theta^{\text {sto }}$. In addition to the baseline case where any trend is ignored we consider three deterministic time trend specifications. In none of the trend specifications do we introduce an intercept because it would not be possible to identify separately the intercept of the trend from the intercept of the inverse demand function since both would be determined by the mean level of observed prices.

\subsection{Trend specifications}

No trend Our benchmark situation is where observed prices are assumed to be without trend. In this case, $\Gamma\left(t, \theta^{\Gamma}\right)=0, P_{t}^{\text {obs }}=P_{t}^{\text {sto }}$, and $\theta^{\Gamma}$ is empty.

Linear trend Here we assume the trend is a deterministic linear time trend:

$$
\Gamma\left(t, \theta^{\Gamma}\right)=g_{1} t
$$

In this case $\theta^{\Gamma}=\left\{g_{1}\right\}$. For numerical stability, the time variable, $t$, is taken to vary between -1 and 1 .

Restricted cubic splines While the linear trend allows us to capture the overall long-run trend, it may not capture all the non-cyclical fluctuations that the storage model is unable to explain. It is often considered that trends in commodity prices might be non-constant (a feature captured, e.g., in Arezki et al., 2014, by a piecewise linear trend with structural breaks). For a more flexible trend than in the linear case, we use restricted cubic splines. Cubic splines are piecewise cubic polynomials with continuous first and second derivatives. "Restricted" splines are splines that are constrained to be linear beyond the boundary knots which avoids a poor behavior in the tails, a feature common to polynomial trends. A restricted cubic spline with three knots has two parameters. With four knots, it has three parameters. So restricted cubic splines with three and four knots have the same degrees of freedom as quadratic and cubic polynomials but tend to be slightly more flexible. A spline with two knots would be the same as the linear trend above. Restricted cubic splines with three to five knots are also used in Roberts and Schlenker (2013) to capture trends in prices and quantities of agricultural commodities.

When represented by restricted cubic splines, the trend is expressed as

$$
\Gamma\left(t, \theta^{\Gamma}\right)=\sum_{i=1}^{I} g_{i} B_{i}(t),
$$

where $I$ and $B_{i}(\cdot)$ are the degree of freedom and the basis functions of the spline, ${ }^{5}$ and $g_{i}$ are the trend parameters to be estimated. The $B_{i}(\cdot)$ are functions of the knots, but once the knots are fixed the trend is linear in its parameters. Following the heuristics proposed in Harrell (2001), the knots for the

\footnotetext{
${ }^{5}$ For numerical stability, the splines are expressed in B-spline form and their basis matrices come from the command ns in the R package splines.
} 
cubic spline with three knots are located at the 10th, 50th, and 90th quantiles of the covariate, which correspond in our 1900-2011 sample to the years 1911, 1956, and 2000. The spline with four knots uses as knots the 5th, 35th, 65th, and 95th quantiles (1905, 1939, 1970, and 2006).

Since the knots are fixed before the estimation, only the slope parameters have to be estimated: $\theta^{\Gamma}=\left\{g_{i}\right\}_{i=1}^{I}$.

\subsection{The likelihood estimator}

Given that the price function $\mathcal{P}$ is strictly decreasing (Cafiero et al., 2011b), we can invert it to obtain the amount on hand from the price. Using the inverse of the price function, the cyclical component of prices, $P^{\text {sto }}$, follows a first-order Markov process with the transition equation defined by equations (3) and (6) as

$$
P_{t}^{\text {sto }}=\mathcal{P}\left(\mathcal{P}^{-1}\left(P_{t-1}^{\text {sto }}\right)-D\left(P_{t-1}^{\text {sto }}\right)+\epsilon_{t}\right) .
$$

It is possible to link $P_{t}^{\text {sto }}$ to observed prices, $P_{t}^{\text {obs }}$, using equation (9). So, given the price function $\mathcal{P}$, equations (9) and (12) define a mapping from the supply shocks $\epsilon_{t}$ to $P_{t}^{\text {obs }}$, conditional on $P_{t-1}^{\text {obs }}$ and $t$.

Given a set of model parameters $\theta$ and a sample of observed prices of length $T$, noted $P_{1 \cdot T}^{\text {obs }} \equiv$ $\left\{P_{1}^{\text {obs }}, \ldots, P_{T}^{\text {obs }}\right\}$, and using the Markov structure of the problem, the likelihood function can be expressed as

$$
L\left(\theta ; P_{1: T}^{\mathrm{obs}}\right)=f\left(P_{1}^{\mathrm{obs}} ; \theta\right) \prod_{t=2}^{T} f\left(P_{t}^{\mathrm{obs}} \mid P_{t-1}^{\mathrm{obs}} ; \theta\right) .
$$

Using the mapping between observables and shocks, Miranda and Rui (1999) and Cafiero et al. (2015) obtain the conditional density $f\left(P_{t}^{\text {obs }} \mid P_{t-1}^{\text {obs }} ; \theta\right)$ from the variable transformation method. Identification of the parameters of the demand function requires the parameters of the distribution of shocks to be set to arbitrary values. From here, the distribution of $\epsilon$ is assumed to be the unit normal distribution truncated at five standard deviations, with probability density function $f_{\epsilon}(\epsilon)=\phi(\epsilon) /[\Phi(5)-\Phi(-5)]$ for $\epsilon \in[-5,5]$ and $f_{\epsilon}(\epsilon)=0$ otherwise. We can write the conditional density of $P_{t}^{\text {obs }}$ as:

$$
f\left(P_{t}^{\mathrm{obs}} \mid P_{t-1}^{\mathrm{obs}} ; \theta\right)=f_{\epsilon}\left(\epsilon_{t}\right)\left|J_{t}\right|
$$

where $\left|J_{t}\right|$ is the determinant of the Jacobian of the mapping $P_{t}^{\text {obs }} \mapsto \epsilon_{t}$.

Based on equations (9) and (12), this mapping is

$$
\begin{aligned}
\epsilon_{t} & =\mathcal{P}^{-1}\left(P_{t}^{\text {sto }}\right)-\left[\mathcal{P}^{-1}\left(P_{t-1}^{\text {sto }}\right)-D\left(P_{t-1}^{\text {sto }}\right)\right], \\
& =\mathcal{P}^{-1}\left(\mathrm{e}^{-\Gamma\left(t, \theta^{\Gamma}\right)} P_{t}^{\mathrm{obs}}\right)-\left[\mathcal{P}^{-1}\left(\mathrm{e}^{-\Gamma\left(t-1, \theta^{\Gamma}\right)} P_{t-1}^{\mathrm{obs}}\right)-D\left(\mathrm{e}^{-\Gamma\left(t-1, \theta^{\Gamma}\right)} P_{t-1}^{\mathrm{obs}}\right)\right],
\end{aligned}
$$

which gives the expression of $J_{t}$ :

$$
J_{t}=\mathrm{e}^{-\Gamma\left(t, \theta^{\Gamma}\right)} \mathcal{P}^{-1^{\prime}}\left(\mathrm{e}^{-\Gamma\left(t, \theta^{\Gamma}\right)} P_{t}^{\mathrm{obs}}\right) .
$$

The probability of any element of $P_{1: T}^{\text {sto }}$ being equal to $P^{*}$ is zero, so the derivative of $\mathcal{P}^{-1}$ exists almost everywhere.

In this paper we extend the Conditional Maximum Likelihood Estimator pioneered by Cafiero et al. (2015) to its unconditional counterpart. The aim is to use all the available information from the first 
observation by accounting for the marginal density $f\left(P_{1}^{\text {obs }} ; \theta\right)$ in equation (13). The marginal density $f\left(P_{1}^{\text {obs }} ; \theta\right)$ can be expressed as the following integral over the steady-state distribution:

$$
f\left(P_{1}^{\mathrm{obs}} ; \theta\right)=\int_{P_{0}} f\left(P_{1}^{\mathrm{obs}} \mid P_{0} ; \theta\right) f\left(P_{0} ; \theta\right) \mathrm{d} P_{0}
$$

This integral is intractable, because there is no closed-form solution for the steady-state distribution of the storage model. However, we can draw from the distribution with density $f\left(P_{0} ; \theta\right)$, which is the unconditional probability density function of price in the storage model. Therefore, we can use Monte Carlo integration to estimate $f\left(P_{1}^{\text {obs }} ; \theta\right)$ by simulating the model on the stationary distribution:

$$
f\left(P_{1}^{\mathrm{obs}} ; \theta\right) \approx M^{-1} \sum_{m=1}^{M} f\left(P_{1}^{\mathrm{obs}} \mid P_{0}^{(m)} ; \theta\right),
$$

where $m=\{1, \ldots, M\}$ indexes random draws from the unconditional price distribution. We set the number of draws $M$ to $1,000,000$ and obtain them by simulating 10,000 trajectories starting from the steady state for 120 periods and discarding the first 20 periods as burn-in periods. The random production shocks that generate the price simulations are drawn at the beginning of the estimation procedure and remain fixed throughout. Because of this simulation step, the Unconditional Maximum Likelihood Estimator falls within the class of simulated estimators.

As is well known in time-series econometrics (Hamilton, 1994, Ch. 5), if the sample size is sufficiently large the contribution of the first observation to the likelihood is negligible, while it is often much more complex to calculate the unconditional likelihood than the conditional likelihood. In the case of the storage model, it is true that the simulations necessary to calculate the marginal density make the likelihood evaluation much more costly. In Monte Carlo experiments designed following Michaelides and $\mathrm{Ng}$ (2000) and Cafiero et al. (2015), the unconditional likelihood performs only marginally better than the conditional likelihood. ${ }^{6}$ However, when using an actual sample, the unconditional likelihood has benefits which in our view outweigh its costs. For observed prices the conditional likelihood presents many local optima. The unconditional likelihood helps to select an optimum with an unconditional price distribution not too far from the price sample which may not be the case for a conditional likelihood. Indeed, in order to fit the high serial correlation of the data, the Conditional Maximum Likelihood Estimator often leads to parameter estimates for which the availabilities corresponding to observed prices (calculated using $\mathcal{P}^{-1}$ ) are set at very high levels which would correspond to very high stock levels. Observing large stock levels may have a high probability conditional on having large stocks in the previous period, but the unconditional probability of such a situation is very low. So, the Unconditional Maximum Likelihood Estimator helps to filter out some of these situations.

Based on all the previous elements, we can write the log-likelihood as

$$
\begin{aligned}
\log L\left(\theta ; P_{1: T}^{\mathrm{obs}}\right) & =-\frac{T}{2} \log 2 \pi-T \log [\Phi(5)-\Phi(-5)]+\sum_{t=1}^{T}\left[-\Gamma\left(t, \theta^{\Gamma}\right)+\log \left|\mathcal{P}^{-1^{\prime}}\left(\mathrm{e}^{-\Gamma\left(t, \theta^{\Gamma}\right)} P_{t}^{\mathrm{obs}}\right)\right|\right] \\
& -\sum_{t=2}^{T}\left(1_{\left|\epsilon_{t}\right| \leq 5} \cdot \epsilon_{t}^{2}+1_{\left|\epsilon_{t}\right|>5} \cdot \infty\right) / 2+\log \left(M^{-1} \sum_{m=1}^{M} 1_{\left|\epsilon^{(m)}\right| \leq 5} \cdot \exp \left(-\epsilon^{(m)^{2}} / 2\right)\right), \quad(19)
\end{aligned}
$$

${ }^{6}$ Results available in section A3 of the online appendix. 
where 1 is the indicator function and $\epsilon^{(m)}=\mathcal{P}^{-1}\left(\exp \left(-\Gamma\left(1, \theta^{\Gamma}\right)\right) P_{1}^{\text {obs }}\right)-S_{0}^{(m)}$. Given that the interest rate and the parameters of the distribution of production shocks have been fixed, there are three parameters that we need to estimate for the storage model $\theta^{\text {sto }}=\{a, b, k\}$, in addition to the parameters characterizing the trend, $\theta^{\Gamma}$, defined above. From a set of parameters $\theta$ provided by the optimization algorithm, we calculate the detrended price $P^{\text {sto }}$ and solve for the policy function of the storage model $\mathcal{P}(\cdot)$. Using this policy function, we can simulate the model to calculate the marginal probability and evaluate the likelihood for this set of parameters.

Evaluated on the observed prices, the above log-likelihood behaves badly. It displays many local optima. Gradient-based solvers and derivative-free local search methods converge only to local optima which are very sensitive to first guesses. Thus, we need to apply a global search algorithm to increase the likelihood of obtaining a global solution. Following a recent review of derivative-free algorithms (Rios and Sahinidis, 2013), and some tests on our problem, we choose a global solver, the particle swarm pattern search algorithm proposed by Vaz and Vicente (2007), and refine the solution it delivers with a local solver using a sequential quadratic programming approach (Nocedal and Wright, 2006, Ch. 18). Parameters are constrained to remain within bounds (this is required by the global solver). $b$ is constrained to be strictly negative $(\leq-0.001)$ and $k$ to be positive or null. All the other bounds are chosen to be low enough or high enough to avoid them being binding. The particle swarm solver is initialized with 700 vectors of first-guess parameters, a combination of educated guesses, random draws, and vectors of previous solutions (e.g., the estimation without trend serves as a first guess for the linear trend). The tolerance for both optimization solvers is fixed at $10^{-6}$.

Once a maximum has been identified, we estimate the asymptotic variance-covariance matrix of the parameters as the inverse of the outer product of the scores. If the highest log-likelihood is obtained with $k$ constrained at its zero lower bound, calculating the variance-covariance matrix using the scores is inappropriate, and other methods such as bootstrap should be used. However, the number of our estimations prevents us from using the bootstrap method. For the estimates with $k$ at zero, we do not report the standard errors for $k$ but report the standard errors of the other parameters obtained using the inverse of the outer product of the scores by maintaining $k$ at zero.

\section{Estimation results}

\subsection{Data}

Our data set is composed of the thirteen commodities analyzed in Deaton and Laroque (1992) (banana, cocoa, coffee, copper, cotton, jute, maize, palm oil, rice, sugar, tea, tin, and wheat). The original price series from Grilli and Yang (1988) is extended by Pfaffenzeller et al. (2007) and cover the period 1900 to 2011. The data were downloaded from Stephan Pfaffenzeller's personal website. ${ }^{7}$ The data are annual price indexes calculated by averaging the monthly price data provided by the World Bank Development Prospects Groups over the calendar year, and normalizing them with respect to the 1977-79 mean price. We deflated the nominal price indexes by the US CPI.

We use only price data to estimate the storage model but we also rely on shorter series of production data to illustrate the consequence of our estimations in terms of demand elasticities. The production data are from the FAOSTAT food balance sheets in the case of the agricultural commodities, ${ }^{8}$ from the British Geological Survey in the case of tin, ${ }^{9}$ and from the 2014 World Copper Factbook of the International

\footnotetext{
${ }^{7}$ http://www.stephan-pfaffenzeller.com

8http://faostat.fao.org/

${ }^{9}$ http://www.bgs.ac.uk/mineralsuk/statistics/home.html
} 
Copper Study Group for copper. ${ }^{10}$ They cover the period 1961 to 2011 . For each commodity, the logarithm of production is detrended by modeling the trend by a restricted cubic spline with five knots (as in Roberts and Schlenker, 2013). ${ }^{11}$

\subsection{Model selection}

Joint estimation of the structural and trend parameters allows us to select the preferred trend specification using model selection criteria. We select the preferred trend specification using the Akaike Information Criterion (AIC). The results are reported in table 1 which presents the values for the preferred models in boldface. For the model without trend the AIC is given in level, while for the three models with trend they are given in ratios to the AIC of the model without trend so that a value above unity means a lower AIC than the model without trend. According to the AIC, the model without trend is never retained for any of the commodities. The model with a linear trend is preferred for copper, palm oil, and wheat. The model with a three-knot spline trend (RCS3) is preferred for coffee, cotton, jute, rice, and sugar. The model with a four-knot spline trend (RCS4) is preferred for banana, cocoa, maize, tea, and tin.

Table 1: Model Selection Using the Akaike Information Criterion

\begin{tabular}{lrccr}
\hline Commodity & No trend & Linear & RCS3 & RCS4 \\
\hline Banana & -309.823 & 1.030 & 1.069 & $\mathbf{1 . 0 7 0}$ \\
Cocoa & -417.014 & 0.998 & 1.010 & $\mathbf{1 . 0 2 5}$ \\
Coffee & -377.997 & 0.995 & $\mathbf{1 . 0 0 5}$ & 1.000 \\
Copper & -236.051 & $\mathbf{1 . 0 0 0}$ & 0.993 & 0.997 \\
Cotton & -231.181 & 0.992 & $\mathbf{1 . 0 2 1}$ & 1.011 \\
Jute & -184.036 & 1.015 & $\mathbf{1 . 0 5 6}$ & 1.045 \\
Maize & -159.578 & 0.998 & 1.002 & $\mathbf{1 . 0 3 8}$ \\
Palm oil & -219.800 & $\mathbf{1 . 0 4 2}$ & 1.040 & 1.034 \\
Rice & -219.357 & 1.105 & $\mathbf{1 . 1 1 4}$ & 1.104 \\
Sugar & -93.022 & 1.189 & $\mathbf{1 . 1 9 8}$ & 1.179 \\
Tea & -275.557 & 1.011 & 1.010 & $\mathbf{1 . 0 1 4}$ \\
Tin & -406.411 & 0.996 & 1.006 & $\mathbf{1 . 0 0 6}$ \\
Wheat & -189.445 & $\mathbf{1 . 0 5 4}$ & 1.046 & 1.054 \\
\hline
\end{tabular}

Notes: For the "No trend" column, the AIC are given in levels while for the other columns they are reported in ratios to the "No trend" column so that a value above unity means a lower AIC than the model without trend. The preferred model for each commodity is in boldface.

For the estimations where storage costs are not constrained on their lower bound we also perform likelihood ratio tests to confirm whether the model without trend is rejected (table A4 in online appendix). The model selection is confirmed by the likelihood ratio test: for almost all the selected models with trend the test rejects the null of a model without trend. This is not the case for coffee and copper for which we cannot reject the null at the 5\% threshold, in line with values of AIC that barely exceed under the preferred trends the values without trend. In what follows, to maintain the comparability with the commodities for which the same test cannot be done, we retain as preferred models for coffee and copper those with trend selected by the AIC, but when interpreting the results it

\footnotetext{
10http://www . icsg.org/index.php/statistics/selected-data

${ }^{11}$ The knots are located at 1964, 1975, 1986, 1998, and 2008 as suggested by Harrell (2001).
} 
has to be kept in minds that they do not pass the likelihood ratio test.

\subsection{No trend}

The parameter estimates for the model without trend are given in table 2. In this setting without stock deterioration, estimates of $a$ in the first column are directly interpretable as the ergodic means of the models. Thus, it would be reasonable to expect $a$ to be not too far from the observed sample means reported in table 3, even if the sample mean is not the maximum likelihood estimator of $a$. However, this is not the case. With the exception of sugar, $a$ is systematically higher than the sample mean, and for some commodities by a large margin. For example, $a$ exceeds the sample mean by 255 percent for banana, 227 for cotton, 122 for rice, or 80 for wheat. This "bias" could be related to the presence of a trend in the observables. A trend would generate a serial correlation higher than expected from storage alone. Estimating the ergodic mean of the model at above the sample mean implies that the sample is located in a region of larger than normal availabilities, and with large availabilities there are important stocks, and prices are more positively correlated than if availabilities are close to normal.

The limited number of stockouts confirms that the estimations localize all the samples in regions with large availability. With the exception of palm oil and sugar for which the respective number of periods without stocks over the sample are 1 and 3, commodity prices are always under their respective cutoff price $P^{*}$ implying that inventories were carried over the whole 112 years of the sample. This feature is present also in the estimations in Cafiero et al. (2011b), where only sugar displays stockouts. In the model, stockouts occur when prices exceed $P^{*}$. Our estimations show that on average over all commodities, $P^{*}$ exceeds its corresponding sample means by 4.5 times, making stockouts unlikely. ${ }^{12}$

The small number of stockouts, and localization of the samples in regions with large availabilities question the empirical relevance of the storage model. This model is supposed to alternate between two regimes with relatively stable prices when there are stocks, and spikes during stockouts. If there are no stockouts, price spikes are explained by adverse production shocks only. They do not correspond to a much steeper part of the demand function and should be as likely as price troughs, which is not consistent with the stylized facts. Most commodity prices present a positive skewness (table 3) and there are few downward spikes to match the upward spikes (Deaton and Laroque, 1992).

Section 2.2 showed that the storage model can generate high serial correlation only with parameterization of very low storage cost and very inelastic demand. We next examine the magnitude of the estimated storage costs and demand elasticities. $k / a$ is the ratio of storage cost to the ergodic mean price, so it is unit-free and directly interpretable. Because we assumed that supply shocks follow a truncated unit normal, it is not possible to recover the demand elasticity only from the demand function. To calculate the demand elasticity, we use Deaton and Laroque's (1996) Proposition 1 which shows that re-scaling the distribution of supply shocks to have mean and standard deviation $\mu$ and $\sigma$ while adjusting the inverse demand function to $\tilde{D}^{-1}\left(C_{t}\right)=(a-b \mu / \sigma)+b C_{t} / \sigma$ does not affect the distribution of prices. Using this adjusted demand function, the demand elasticity evaluated at the model's ergodic mean price is given by $a \sigma /(b \mu) .{ }^{13}$ The coefficient of variation of the supply shocks, $\sigma / \mu$, is obtained by calculating the standard deviation of the detrended logarithm of production, and is provided in the online appendix. ${ }^{14}$

\footnotetext{
${ }^{12}$ See section A4 in the online appendix for a graphical illustration.

${ }^{13} \mathrm{~A}$ similar approach is used in Guerra et al. (2015).

${ }^{14}$ While reformulating the estimates as unit-free parameters is necessary to compare them between trend specifications, the expression as a demand elasticity relies on a literal interpretation of the storage model. In this specification of the storage model, additive demand shocks are equivalent to additive negative supply shocks, and thus the supply shocks in the model
} 
Table 2: Parameter Estimates Without Trend

\begin{tabular}{|c|c|c|c|c|c|c|}
\hline Commodity & $a$ & $b$ & $k$ & $\log L$ & $P^{*}$ & \# Stockouts \\
\hline Banana & $\begin{array}{c}1.9078 \\
(0.6159)\end{array}$ & $\begin{array}{c}-3.8117 \\
(2.3678)\end{array}$ & $\begin{array}{c}0.0011 \\
(0.0037)\end{array}$ & 157.9117 & 3.6291 & 0 \\
\hline Cocoa & $\begin{array}{c}0.1826 \\
(0.0383)\end{array}$ & $\begin{array}{c}-0.8604 \\
(0.0930)\end{array}$ & $\begin{array}{c}0.0002 \\
(0.0009)\end{array}$ & 211.5072 & 0.6149 & 0 \\
\hline Coffee & $\begin{array}{c}0.2571 \\
(0.0259)\end{array}$ & $\begin{array}{c}-0.8959 \\
(0.0656)\end{array}$ & $\begin{array}{c}0.0015 \\
(0.0009)\end{array}$ & 191.9984 & 0.6876 & 0 \\
\hline Copper & $\begin{array}{c}0.6339 \\
(0.0540)\end{array}$ & $\begin{array}{c}-1.1740 \\
(0.1382)\end{array}$ & $\begin{array}{c}0.0046 \\
(0.0034)\end{array}$ & 121.0254 & 1.1461 & 0 \\
\hline Cotton & $\begin{array}{c}1.7832 \\
(0.7019)\end{array}$ & $\begin{array}{c}-6.1122 \\
(3.9400)\end{array}$ & $\begin{array}{c}0.0029 \\
(0.0027)\end{array}$ & 118.5906 & 4.7461 & 0 \\
\hline Jute & $\begin{array}{c}0.6934 \\
(0.0970)\end{array}$ & $\begin{array}{c}-1.7440 \\
(0.2308)\end{array}$ & $\begin{array}{c}0.0050 \\
(0.0049)\end{array}$ & 95.0180 & 1.4927 & 0 \\
\hline Maize & $\begin{array}{c}0.7058 \\
(0.0816)\end{array}$ & $\begin{array}{c}-2.3422 \\
(0.1738)\end{array}$ & $\begin{array}{c}0.0009 \\
(0.0030)\end{array}$ & 82.7891 & 1.8374 & 0 \\
\hline Palm oil & $\begin{array}{c}0.7311 \\
(0.0802)\end{array}$ & $\begin{array}{c}-1.5067 \\
(0.1708)\end{array}$ & $\begin{array}{c}0.0097 \\
(0.0046)\end{array}$ & 112.8999 & 1.3887 & 1 \\
\hline Rice & $\begin{array}{c}1.1766 \\
(0.3604)\end{array}$ & $\begin{array}{c}-5.2418 \\
(2.2061)\end{array}$ & $\begin{array}{l}0 \\
-\end{array}$ & 112.6784 & 3.8021 & 0 \\
\hline Sugar & $\begin{array}{c}0.5362 \\
(0.0521)\end{array}$ & $\begin{array}{c}-1.9907 \\
(0.1123)\end{array}$ & $\begin{array}{c}0.0050 \\
(0.0026)\end{array}$ & 49.5109 & 1.4926 & 3 \\
\hline Tea & $\begin{array}{c}1.0839 \\
(0.4672)\end{array}$ & $\begin{array}{c}-3.6411 \\
(2.2116)\end{array}$ & $\begin{array}{l}0 \\
-\end{array}$ & 140.7786 & 2.8518 & 0 \\
\hline Tin & $\begin{array}{c}0.3606 \\
(0.0509)\end{array}$ & $\begin{array}{c}-1.0371 \\
(0.2022)\end{array}$ & $\begin{array}{c}0.0023 \\
(0.0015)\end{array}$ & 206.2057 & 0.8462 & 0 \\
\hline Wheat & $\begin{array}{c}1.0926 \\
(0.1819)\end{array}$ & $\begin{array}{c}-3.9100 \\
(1.0561)\end{array}$ & $\begin{array}{l}0 \\
-\end{array}$ & 97.7225 & 3.0058 & 0 \\
\hline
\end{tabular}

Notes: Asymptotic standard errors in parentheses. Column \# Stockouts indicates the number of times the observed prices are greater than or equal to the cutoff price for no storage: $\sum_{t=1}^{T}{ }^{1} P_{t}^{\text {obs }} \geq P^{*}$.

The estimated storage costs and price elasticities of demand are consistent with the results in section 2.2: both are low (table 4). The estimated storage costs are below 1 percent of the ergodic price for all commodities except palm oil, and are null for three commodities: rice, tea, and wheat. Information on storage costs to which we could compare these estimates are not readily available for all commodities. However, in a study of the grain chain in Middle East and North African countries, World Bank and FAO (2012, figure 2-4) report that the storage cost of wheat in the US was equal to US\$ 24.24 per ton in 2009 , which would represent around $10 \%$ of the recent price of wheat. So, at least for cereals, the estimates of storage costs appear to be low.

In the model without trend, our implied price elasticities of consumption are comparable to those

should be interpreted as net-supply shocks. If we assume that demand and supply shocks are uncorrelated, the elasticities calculated using only the coefficient of variation of supply will be downward biased. For staple food markets, where price volatility is often believed to be primarily driven by supply shocks the bias may be small, but it may be larger for commodities more subject to demand shocks such as metals. 
Table 3: Comparisons of Data Features and Predictions of the Model Without Trend

\begin{tabular}{|c|c|c|c|c|c|c|c|}
\hline Commodity & Variable & Mean & $\begin{array}{c}\text { One-year } \\
\text { a-c }\end{array}$ & $\begin{array}{c}\text { Two-year } \\
\text { a-c }\end{array}$ & $\begin{array}{l}\text { Coefficient } \\
\text { of variation }\end{array}$ & Skewness & $\begin{array}{l}\text { Excess } \\
\text { kurtosis }\end{array}$ \\
\hline \multirow[t]{2}{*}{ Banana } & Observed moments & 0.54 & 0.95 & 0.90 & 0.23 & -0.27 & -0.77 \\
\hline & Model percentiles & 0.00 & 99.99 & 99.97 & 0.09 & 0.00 & 0.15 \\
\hline \multirow[t]{2}{*}{ Cocoa } & Observed moments & 0.17 & 0.86 & 0.71 & 0.60 & 1.24 & 1.64 \\
\hline & Model percentiles & 44.65 & 79.86 & 70.05 & 23.67 & 17.34 & 19.25 \\
\hline \multirow[t]{2}{*}{ Coffee } & Observed moments & 0.20 & 0.84 & 0.68 & 0.50 & 1.61 & 3.89 \\
\hline & Model percentiles & 24.01 & 83.94 & 76.14 & 10.45 & 25.41 & 28.47 \\
\hline \multirow[t]{2}{*}{ Copper } & Observed moments & 0.47 & 0.83 & 0.64 & 0.40 & 0.90 & 0.56 \\
\hline & Model percentiles & 6.22 & 96.47 & 87.84 & 10.72 & 4.30 & 3.92 \\
\hline \multirow[t]{2}{*}{ Cotton } & Observed moments & 0.55 & 0.94 & 0.85 & 0.51 & 0.20 & -0.61 \\
\hline & Model percentiles & 0.55 & 99.74 & 97.75 & 16.38 & 0.19 & 0.71 \\
\hline \multirow[t]{2}{*}{ Jute } & Observed moments & 0.52 & 0.84 & 0.70 & 0.44 & 0.41 & -0.23 \\
\hline & Model percentiles & 13.15 & 92.75 & 89.26 & 8.31 & 0.62 & 1.49 \\
\hline \multirow[t]{2}{*}{ Maize } & Observed moments & 0.61 & 0.86 & 0.73 & 0.51 & 0.84 & 1.22 \\
\hline & Model percentiles & 31.96 & 89.21 & 84.45 & 18.51 & 5.54 & 13.10 \\
\hline \multirow[t]{2}{*}{ Palm oil } & Observed moments & 0.46 & 0.82 & 0.65 & 0.60 & 2.43 & 11.84 \\
\hline & Model percentiles & 2.34 & 95.05 & 89.66 & 48.31 & 50.03 & 71.20 \\
\hline \multirow[t]{2}{*}{ Rice } & Observed moments & 0.53 & 0.91 & 0.79 & 0.50 & 0.42 & -0.39 \\
\hline & Model percentiles & 5.81 & 94.03 & 87.47 & 12.04 & 0.89 & 1.88 \\
\hline \multirow[t]{2}{*}{ Sugar } & Observed moments & 0.61 & 0.70 & 0.51 & 0.69 & 1.62 & 3.45 \\
\hline & Model percentiles & 66.50 & 48.82 & 40.01 & 33.70 & 25.65 & 26.31 \\
\hline \multirow[t]{2}{*}{ Tea } & Observed moments & 0.45 & 0.90 & 0.81 & 0.38 & -0.02 & -0.80 \\
\hline & Model percentiles & 1.63 & 95.84 & 95.15 & 3.18 & 0.03 & 0.31 \\
\hline \multirow[t]{2}{*}{ Tin } & Observed moments & 0.20 & 0.90 & 0.78 & 0.47 & 1.48 & 2.84 \\
\hline & Model percentiles & 3.87 & 98.21 & 95.47 & 9.35 & 19.40 & 20.00 \\
\hline \multirow[t]{2}{*}{ Wheat } & Observed moments & 0.61 & 0.91 & 0.79 & 0.47 & 0.82 & 0.39 \\
\hline & Model percentiles & 6.73 & 96.97 & 91.36 & 12.58 & 5.42 & 6.80 \\
\hline
\end{tabular}

Note: There are two variables for each commodity: the moments calculated on the observed prices, $P^{\text {obs }}$, and below the percentiles corresponding to these moments calculated from the estimated model using $1,000,000$ samples of the same size as the data.

derived from other estimations of the storage model (see table 4 in Guerra et al., 2015). If we focus on the cereals, although these elasticities are plausible, in absolute value they appear to be in the low range of the elasticities in the literature (e.g., Seale and Regmi, 2006; Adjemian and Smith, 2012; Roberts and Schlenker, 2013). We would expect smaller elasticities than in most of the literature because most estimation methods do not account for the presence of stocks which tend to create a positive bias. Nevertheless, even Roberts and Schlenker (2013) who control for the effect of storage using instrumental variables find higher elasticities of demand, between -0.066 and -0.028 for aggregate calories from maize, rice, soybeans and wheat, and even higher values for each commodity individually.

\subsection{Models with a time trend}

For the specifications with trend, since the structural parameters are not directly interpretable, the complete results are not displayed here. They are provided in the online appendix, along with a figure plotting the various trends with real prices. With a linear trend (table A6 in the online appendix), for all commodities except tin, the annual growth rate is negative, which is consistent with the Prebisch-Singer 
Table 4: Estimated Values of Storage Costs and Demand Elasticities

\begin{tabular}{|c|c|c|c|c|c|c|c|c|}
\hline \multirow[b]{2}{*}{ Commodity } & \multicolumn{4}{|c|}{ Storage costs: $100 \cdot k / a$} & \multicolumn{4}{|c|}{ Price elasticity of demand: $a \sigma /(b \mu)$} \\
\hline & No trend & Linear & RCS3 & RCS4 & No trend & Linear & RCS3 & RCS4 \\
\hline \multirow[t]{2}{*}{ Banana } & 0.06 & 0 & 0 & $\mathbf{0}$ & -0.018 & -0.033 & -0.029 & -0.029 \\
\hline & $(0.19)$ & - & - & - & (0.013) & $(0.004)$ & (0.009) & $(0.008)$ \\
\hline \multirow[t]{2}{*}{ Cocoa } & 0.11 & 0.19 & 0.05 & 0.53 & -0.015 & -0.015 & -0.015 & $-\mathbf{0 . 0 2 7}$ \\
\hline & $(0.51)$ & $(0.54)$ & $(0.23)$ & $(0.63)$ & (0.004) & $(0.004)$ & $(0.010)$ & $(0.009)$ \\
\hline \multirow[t]{2}{*}{ Coffee } & 0.59 & 0.59 & 1.41 & 1.41 & -0.022 & -0.022 & $-\mathbf{0 . 0 3 7}$ & -0.037 \\
\hline & $(0.35)$ & $(0.35)$ & $(1.01)$ & (1.07) & (0.003) & $(0.003)$ & $(0.010)$ & $(0.010)$ \\
\hline \multirow[t]{2}{*}{ Copper } & 0.72 & 1.09 & 0.99 & 0.07 & -0.024 & -0.028 & -0.028 & -0.019 \\
\hline & $(0.54)$ & $(0.67)$ & $(0.70)$ & $(0.59)$ & (0.004) & $(0.004)$ & $(0.005)$ & $(0.005)$ \\
\hline \multirow[t]{2}{*}{ Cotton } & 0.16 & 0.19 & 0.34 & 0.34 & -0.021 & -0.022 & -0.029 & -0.029 \\
\hline & $(0.17)$ & $(0.43)$ & $(0.43)$ & $(0.50)$ & (0.016) & $(0.038)$ & $(0.015)$ & $(0.020)$ \\
\hline \multirow[t]{2}{*}{ Jute } & 0.72 & 0.42 & 2.35 & 2.34 & -0.045 & -0.045 & -0.104 & -0.104 \\
\hline & $(0.71)$ & $(0.96)$ & $(0.91)$ & (0.99) & (0.009) & $(0.008)$ & (0.009) & $(0.015)$ \\
\hline \multirow[t]{2}{*}{ Maize } & 0.13 & 1.07 & 1.34 & 3.25 & -0.018 & -0.030 & -0.036 & -0.062 \\
\hline & $(0.43)$ & $(0.83)$ & $(0.80)$ & $(0.75)$ & (0.002) & $(0.004)$ & $(0.005)$ & $(0.005)$ \\
\hline \multirow[t]{2}{*}{ Palm oil } & 1.33 & 1.20 & 1.40 & 1.43 & -0.023 & -0.027 & -0.028 & -0.028 \\
\hline & $(0.64)$ & $(0.91)$ & $(0.88)$ & $(0.98)$ & (0.004) & $(0.004)$ & (0.004) & $(0.008)$ \\
\hline \multirow[t]{2}{*}{ Rice } & 0 & 0.28 & 0.30 & 0.33 & -0.006 & -0.014 & -0.016 & -0.016 \\
\hline & - & $(0.51)$ & $(0.54)$ & $(0.55)$ & $(0.003)$ & $(0.002)$ & (0.004) & $(0.005)$ \\
\hline \multirow[t]{2}{*}{ Sugar } & 0.94 & 2.27 & 2.43 & 2.35 & -0.010 & -0.020 & -0.019 & -0.019 \\
\hline & $(0.49)$ & $(0.81)$ & (1.03) & $(0.99)$ & $(0.001)$ & $(0.002)$ & $(0.002)$ & $(0.003)$ \\
\hline \multirow[t]{2}{*}{ Tea } & 0 & 0.57 & 0.95 & 0.89 & -0.006 & -0.011 & -0.014 & -0.014 \\
\hline & - & $(0.36)$ & $(0.51)$ & $(0.46)$ & $(0.005)$ & $(0.002)$ & $(0.004)$ & $(0.005)$ \\
\hline \multirow[t]{2}{*}{ Tin } & 0.63 & 0.26 & 0 & $\mathbf{0}$ & -0.019 & -0.015 & -0.014 & -0.017 \\
\hline & $(0.43)$ & $(0.21)$ & - & - & $(0.005)$ & $(0.005)$ & $(0.003)$ & $(0.002)$ \\
\hline \multirow[t]{2}{*}{ Wheat } & 0 & 1.11 & 1.18 & 0 & -0.012 & -0.033 & -0.034 & -0.025 \\
\hline & - & $(0.77)$ & $(0.80)$ & - & $(0.004)$ & $(0.005)$ & $(0.005)$ & $(0.005)$ \\
\hline
\end{tabular}

Notes: The preferred model values are in boldface and in parentheses the asymptotic standard errors obtained using the delta method. Storage costs are expressed unit-free as a percentage of the ergodic mean price: $a$. The price elasticity of demand is evaluated at the ergodic mean price using the coefficient of variation of production (table A5 in the online appendix).

hypothesis of a long-run downward trend in commodity prices. If we exclude coffee and tin, the values range from an annual decline of 0.4 percent for copper to 1.94 percent for rice. The significance of many trend coefficients indicates that the model without trend is likely to be misspecified.

Table 4 presents the parameters estimates expressed in a way that makes them comparable across trend specifications. The presence of a deterministic time trend in the model estimation can lead to large effects in terms of the key parameter estimates. Storage costs tend to increase when there is a trend, and also price elasticity of demand in absolute value. With the preferred model (in boldface) ten out of the thirteen commodities present higher storage costs than if there is no trend. With the exception of tin, all price elasticities are higher with the preferred model. The differences between the elasticities estimated with the models without trend and with the preferred models with trend are important. The elasticities double in the case of cocoa, coffee, jute, rice, sugar, and tea, and increase three-fold for maize and wheat.

For cereals, the elasticities of the preferred model although still low appear to be more consistent with the literature. Similarly, the increase in storage costs for cereals leads to more plausible parameters 
which nevertheless are low compared to some published figures.

For sugar, we can compare the parameter estimates to the Conditional Maximum Likelihood estimates of Cafiero et al. (2015). They estimate their model on data from 1921 to 2009, because of a possible structural break between 1920 and 1921. On this subsample, the stationarity of deflated prices is more likely to hold (see figure A2 in the online appendix) and the first-order autocorrelation at 0.63 is lower than the 0.70 obtained over our extended sample. The purpose of our joint estimation approach is precisely to accommodate for such possible breaks. The preferred model for sugar is the model with a three-knot spline trend. The estimated trend is decreasing at the beginning of the sample and roughly constant after 1930 (figure A2 in the online appendix). We express the parameters in ratios to make them comparable across specifications. For $100 \cdot k / a$, our estimation is 2.43 (table A7 in the online appendix) and theirs is 2.23 (Cafiero et al., 2015, Table 3, ML setting $d=0$ ). For $a / b$, our estimation is -0.52 and theirs is -0.49 . The estimations are very close, while they are very different if we use our estimation without trend $(100 \cdot k / a=0.94$ and $a / b=-0.27)$. This could indicate that for sugar our strategy succeeds in removing a source of non-stationarity in the original series.

\subsection{Model predictions}

Since one of the main critiques of the storage model is its inability to reproduce the observed serial correlation, one way to assess our new estimates is to compare the model predictions to the features of the data. For samples of the same length of the observables, a storage model generates moments that are highly volatile, so comparing the ergodic moments and observed moments would be inappropriate. We adopt the approach in Cafiero et al. (2011b): we match the observed moments to their corresponding percentiles in the ergodic distribution of the estimated model. The model predictions are consistent with the data when the percentiles are neither too low nor too high. We calculate the mean, first- and second-order autocorrelations, coefficient of variation, skewness, and kurtosis for the observations. For the model with trend, the moments are calculated on the cyclical component of prices, $P^{\text {sto }}$, which is the component that the storage model is supposed to explain. We calculate the corresponding percentiles using 1,000,000 series of 112 periods from the asymptotic distribution.

The moments and their localization with respect to simulated percentiles are given in table 3 for the model without trend and in table 5 for the preferred model with trend. All moments from the observations are located within the implied empirical distribution of the models without and with trend. As already noted by Cafiero et al. (2011b), if the model without trend is solved and estimated with a sufficiently precise grid, it is able to generate first-order autocorrelation similar to the observations for several commodities (table 3), but except for sugar the observed autocorrelation corresponds to high model percentiles. The storage model even appears to fail more often to reproduce the skewness and kurtosis, with observed moments which are frequently below the 0.5 and 2.5 percentiles calculated from the estimated model. It should be noted that the banana and tea price series present negative skewness, which makes them nearly impossible to reproduce with a storage model which on average generates positive skewness. When a commodity presents negative excess kurtosis, which is the case of banana, cotton, jute, rice and tea, it seems that the estimated model has difficulty reproducing it. Deaton and Laroque (1992, section 2.1) note that the storage model can produce negative excess kurtosis but only from a calibration with low price volatility and a limited role for storage, which does not correspond to our estimations.

We turn next to the predictions of the preferred model with trend (table 5). Compared to the model without trend, several commodities show an improvement in the model predictions with many moments closer to central percentiles. However, the predictions for some commodities - banana, 
Table 5: Comparisons of Data Features and Predictions of the Preferred Models

\begin{tabular}{llrrrrrr}
\hline \multirow{2}{*}{ Commodity } & Variable & Mean & $\begin{array}{c}\text { One-year } \\
\text { a-c }\end{array}$ & $\begin{array}{c}\text { Two-year } \\
\text { a-c }\end{array}$ & $\begin{array}{c}\text { Coefficient } \\
\text { of variation }\end{array}$ & Skewness & $\begin{array}{r}\text { Excess } \\
\text { kurtosis }\end{array}$ \\
\hline Banana & Observed moments & 0.66 & 0.89 & 0.81 & 0.41 & 1.66 & 3.25 \\
& Model percentiles & 0.00 & 99.91 & 99.85 & 52.12 & 16.70 & 14.11 \\
Cocoa & Observed moments & 0.43 & 0.82 & 0.65 & 0.61 & 1.76 & 3.00 \\
& Model percentiles & 41.42 & 87.37 & 78.94 & 43.42 & 25.63 & 19.62 \\
& Observed moments & 0.21 & 0.78 & 0.59 & 0.47 & 1.86 & 5.97 \\
Copper & Model percentiles & 17.51 & 89.71 & 79.53 & 12.28 & 24.70 & 34.73 \\
& Observed moments & 0.47 & 0.80 & 0.58 & 0.38 & 0.81 & 0.32 \\
Cotton & Model percentiles & 4.15 & 96.49 & 85.48 & 8.47 & 2.51 & 2.07 \\
& Observed moments & 0.79 & 0.66 & 0.43 & 0.45 & 3.38 & 19.96 \\
Jute & Model percentiles & 1.10 & 50.83 & 30.57 & 14.14 & 78.57 & 86.69 \\
& Observed moments & 0.62 & 0.69 & 0.40 & 0.31 & 0.62 & 0.17 \\
Maize & Model percentiles & 16.66 & 94.09 & 66.04 & 1.86 & 0.34 & 0.32 \\
& Observed moments & 0.85 & 0.69 & 0.46 & 0.36 & 1.47 & 2.79 \\
Palm oil & Model percentiles & 14.25 & 97.76 & 89.60 & 11.28 & 13.80 & 20.66 \\
& Observed moments & 0.42 & 0.72 & 0.47 & 0.39 & 0.99 & 1.38 \\
Rice & Model percentiles & 23.12 & 82.59 & 57.23 & 7.25 & 4.54 & 5.59 \\
& Observed moments & 0.97 & 0.76 & 0.46 & 0.38 & 2.17 & 7.07 \\
Sugar & Model percentiles & 9.98 & 85.62 & 48.62 & 13.20 & 37.65 & 43.28 \\
& Observed moments & 0.93 & 0.62 & 0.35 & 0.67 & 3.00 & 13.73 \\
Tea & Model percentiles & 41.58 & 61.20 & 28.82 & 66.35 & 79.40 & 83.03 \\
& Observed moments & 0.67 & 0.91 & 0.85 & 0.46 & 0.46 & 0.01 \\
Tin & Model percentiles & 0.06 & 99.97 & 99.97 & 38.81 & 0.53 & 1.24 \\
\multirow{2}{*}{ Wheat } & Observed moments & 0.11 & 0.80 & 0.65 & 0.58 & 1.63 & 3.27 \\
& Model percentiles & 15.62 & 71.70 & 67.45 & 33.05 & 26.89 & 26.53 \\
& Observed moments & 0.57 & 0.75 & 0.45 & 0.31 & 1.26 & 2.17 \\
& Model percentiles & 4.09 & 94.87 & 64.47 & 2.55 & 6.11 & 6.88 \\
\hline
\end{tabular}

Note: There are two variables for each commodity: the moments calculated on the cyclical component of prices, $P^{\text {sto }}$, and below the percentiles corresponding to these moments calculated from the estimated model using 1,000,000 samples of the same size as the data.

jute, and tea - do not improve. The storage model with the specifications we estimated seems unable to match the moments for these three commodities. Due to the deterministic trend, observed firstorder autocorrelation decreases but does not become systematically more consistent with the model predictions, because with estimations of higher storage costs and more elastic demand the capacity of the storage model to generate high serial correlation decreases also. For cocoa and maize, the percentiles corresponding to the observed first-order autocorrelation increase significantly toward higher values indicating a decrease in the ability of the model to reproduce this moment. Regarding the second-order autocorrelation, the skewness, and the excess kurtosis, the preferred detrended models are much more able to fit the observed moments than the models without trend. Similarly, if we exclude banana, jute and tea, and with the exception of 3 moments that are outside of the $(2.5,97.5)$ percentiles, all other moments are consistent with the predictions of the estimated storage models.

A disturbing feature of the estimations without trend is the very small number (often zero) of implied stockouts. Considering the possibility of a trend increases the number of implied stockouts, which becomes positive for many commodities (table 6). However, even if we exclude banana, jute and tea, three commodities - cocoa, copper, and cotton - present zero stockouts. It is also interesting to 
compare the number of implied stockouts to the probabilities of exceeding a given number of stockouts. The probabilities of stockouts are calculated in the same way as the price moments using 1,000,000 series of 112 periods from the asymptotic distribution. The results for the model without trend and for the preferred model with trend for at least 1, 2, 5, and 10 stockouts are given in table 6. Models with trend have much higher probabilities of stockouts than the model without trend. If there is a trend, the storage costs and the price elasticities are higher than without trend which discourages storage and leads to higher probabilities of stockouts. Apart from cocoa, cotton and tin, with the preferred model samples without stockouts are highly unlikely. Even samples with only one stockout are fairly unlikely. The parameterization implied by the estimation of a model with trend is much more favorable to occasional stockouts and so provides a natural explanation for price spikes as periods where stocks are exhausted.

Table 6: Number of Implied Stockouts over the Sample Interval and Probabilities of at Least $n$ Stockouts, in Samples of the Same Size as the Data

\begin{tabular}{|c|c|c|c|c|c|c|c|c|c|c|}
\hline \multirow[b]{3}{*}{ Commodity } & \multicolumn{5}{|c|}{ No-trend model } & \multicolumn{5}{|c|}{ Preferred model } \\
\hline & \multirow[b]{2}{*}{ \# Stockouts } & \multicolumn{4}{|c|}{ Probabilities } & \multirow[b]{2}{*}{ \# Stockouts } & \multicolumn{4}{|c|}{ Probabilities } \\
\hline & & $n=1$ & $n=2$ & $n=5$ & $n=10$ & & $n=1$ & $n=2$ & $n=5$ & $n=10$ \\
\hline Banana & 0 & 0.91 & 0.81 & 0.48 & 0.13 & 0 & 0.98 & 0.94 & 0.73 & 0.30 \\
\hline Cocoa & 0 & 0.63 & 0.47 & 0.18 & 0.02 & 0 & 0.86 & 0.74 & 0.39 & 0.09 \\
\hline Coffee & 0 & 0.77 & 0.63 & 0.28 & 0.05 & 1 & 0.95 & 0.88 & 0.59 & 0.19 \\
\hline Copper & 0 & 0.95 & 0.88 & 0.59 & 0.19 & 0 & 0.98 & 0.94 & 0.72 & 0.29 \\
\hline Cotton & 0 & 0.75 & 0.60 & 0.26 & 0.05 & 0 & 0.87 & 0.75 & 0.41 & 0.10 \\
\hline Jute & 0 & 0.88 & 0.77 & 0.43 & 0.10 & 4 & 1.00 & 0.99 & 0.95 & 0.68 \\
\hline Maize & 0 & 0.76 & 0.61 & 0.27 & 0.05 & 12 & 1.00 & 1.00 & 0.99 & 0.86 \\
\hline Palm oil & 1 & 0.95 & 0.88 & 0.59 & 0.19 & 1 & 0.97 & 0.92 & 0.68 & 0.26 \\
\hline Rice & 0 & 0.64 & 0.49 & 0.19 & 0.02 & 1 & 0.95 & 0.88 & 0.59 & 0.19 \\
\hline Sugar & 3 & 0.77 & 0.63 & 0.28 & 0.05 & 8 & 0.98 & 0.94 & 0.73 & 0.30 \\
\hline Tea & 0 & 0.74 & 0.60 & 0.26 & 0.04 & 0 & 0.98 & 0.94 & 0.73 & 0.30 \\
\hline Tin & 0 & 0.84 & 0.71 & 0.36 & 0.08 & 6 & 0.75 & 0.60 & 0.26 & 0.04 \\
\hline Wheat & 0 & 0.72 & 0.57 & 0.24 & 0.04 & 1 & 0.99 & 0.97 & 0.82 & 0.41 \\
\hline
\end{tabular}

Notes: The preferred model is chosen according to the AIC of table 1. The number of implied stockouts is calculated as

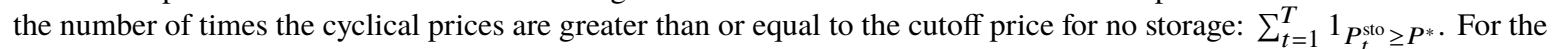
specification without trend, cyclical prices are just observed prices. The probabilities are calculated for each model as the proportion of simulated samples where prices are greater than or equal to the cutoff price for no storage at least $n$ times. The calculation is done on 1,000,000 samples of 112 periods from the asymptotic distribution simulated using the estimated model.

\section{Conclusion}

Estimating the competitive storage model on untransformed series of commodity prices leads to very low demand elasticities and storage costs, which results in a prediction of very infrequent, and often zero, stockouts over the sample period. These results may stem from the presence of trends in prices, which could create statistical features difficult to explain by a storage model.

This article proposes a strategy inspired by Canova (2014) to estimate jointly the structural parameters of a storage model and the parameters characterizing the non-cyclical component of prices for which the storage model cannot account. For the non-cyclical component of prices, three deterministic time trends with increasing flexibility were tested and compared with the baseline model which ignores the 
possibility of a trend.

Our results show that storage models with trend are always preferred to models without trend, and the significance of the trend parameters indicates that the model without trend is likely to be misspecified. Accounting for a trend is quantitatively important for estimating the structural parameters. For most commodities, the storage model with a deterministic trend yields more plausible estimates of the structural parameters (e.g., higher storage costs and demand elasticities). It also increases the probability of observing stockouts, and more closely replicates the most salient features of the price data. For most commodities our results support the empirical relevance of the speculative storage model which is in line with the recent findings in Cafiero et al. $(2011 \mathrm{~b}, 2015)$ and prove that the joint estimation approach is a superior procedure to fit the storage model with the data. Future estimations of the storage model should no longer neglect the possibility of long-run trends in prices.

For banana, jute and tea, three of the commodities originally studied in Deaton and Laroque (1992), the storage model with or without a deterministic trend fails to reproduce the main features of the price dynamics. With the trend specifications considered in this paper, the storage model is rejected as a relevant model to explain the price dynamics of these commodities. However, other specifications could be explored in the future.

This paper is a first step toward jointly analyzing short- and long-run aspects of commodity prices. Our focus was to show the importance of accounting for long-run trends when estimating the storage model, so we have purposefully chosen simple deterministic trends that maintain the tractability of the likelihood, but more sophisticated trend specifications could permit the reconciliation of two branches of the literature that have long been separated. Because commodity prices are characterized by "small trends and big variability" (Cashin and McDermott, 2002), without good explanations for the big short-run variability it is challenging to identify the trends. Conversely, neglecting trends, even small ones, creates difficulties to explain the short-run variability. To really integrate these two issues, several challenges will have to be faced. A storage model in which agents account for trends implies theoretical restrictions such as an isoelastic demand function that create numerical difficulties for the solution method. More sophisticated trends specifications such as random walk with drift or log-linear trend with Markov switching slope would prevent a direct calculation of the likelihood and would require the use of filters for non-linear state-space models (see e.g., Fernández-Villaverde and Rubio-Ramírez, 2007 , for use of the particle filter to estimate macroeconomic models). Some of the pieces are already provided in Zeng (2012), with a storage model including a structural log-linear trend in prices, and Dvir and Rogoff (2014), with a storage model including a trend for quantities following a random walk with drift, but further elaborations are needed to reach the level of sophistication achieved in the literature on trends (Ghoshray, 2011).

\section{References}

Adjemian MK, Smith A. 2012. Using USDA forecasts to estimate the price flexibility of demand for agricultural commodities. American Journal of Agricultural Economics 94: 978-995.

Arezki R, Hadri K, Loungani P, Rao Y. 2014. Testing the Prebisch-Singer hypothesis since 1650: Evidence from panel techniques that allow for multiple breaks. Journal of International Money and Finance 42: 208-223.

Balagtas JV, Holt MT. 2009. The commodity terms of trade, unit roots, and nonlinear alternatives: A smooth transition approach. American Journal of Agricultural Economics 91: 87-105.

Bobenrieth ESA, Bobenrieth JRA, Wright BD, Zeng D. 2014. How biofuels policies boosted grain staple 
prices: A counterfactual analysis. Paper 5125, Agricultural and Applied Economics Association, 2014 Annual Meeting, July 27-29, 2014, Minneapolis, Minnesota.

Bobenrieth ESA, Wright BD, Zeng D. 2013. Stocks-to-use ratios as indicators of vulnerability to spikes in global cereal markets. Agricultural Economics 44: 43-52.

Cafiero C, Bobenrieth ESA, Bobenrieth JRA. 2011a. Storage arbitrage and commodity price volatility. In Prakash A (ed.) Safeguarding food security in volatile global markets, chapter 15. Rome: FAO, 288-313.

Cafiero C, Bobenrieth ESA, Bobenrieth JRA, Wright BD. 2011b. The empirical relevance of the competitive storage model. Journal of Econometrics 162: 44-54.

Cafiero C, Bobenrieth ESA, Bobenrieth JRA, Wright BD. 2015. Maximum Likelihood estimation of the standard commodity storage model: Evidence from sugar prices. American Journal of Agricultural Economics 97: 122-136.

Canova F. 1998. Detrending and business cycle facts: A user's guide. Journal of Monetary Economics 41: 533-540.

Canova F. 2014. Bridging DSGE models and the raw data. Journal of Monetary Economics 67: 1-15.

Cashin P, McDermott CJ. 2002. The long-run behavior of commodity prices: Small trends and big variability. IMF Staff Papers 49: 175-199.

Cuddington JT, Nülle G. 2014. Variable long-term trends in mineral prices: The ongoing tug-of-war between exploration, depletion, and technological change. Journal of International Money and Finance 42: 224-252.

Deaton A, Laroque G. 1992. On the behaviour of commodity prices. Review of Economic Studies 59: $1-23$.

Deaton A, Laroque G. 1996. Competitive storage and commodity price dynamics. Journal of Political Economy 104: 896-923.

Dvir E, Rogoff KS. 2014. Demand effects and speculation in oil markets: Theory and evidence. Journal of International Money and Finance 42: 113-128.

Fernández-Villaverde J, Rubio-Ramírez JF. 2007. Estimating macroeconomic models: A likelihood approach. The Review of Economic Studies 74: 1059-1087.

Ferroni F. 2011. Trend agnostic one-step estimation of DSGE models. The B.E. Journal of Macroeconomics 11: 1-36.

Ghoshray A. 2011. A reexamination of trends in primary commodity prices. Journal of Development Economics 95: 242-251.

Grilli ER, Yang MC. 1988. Primary commodity prices, manufactured goods prices, and the terms of trade of developing countries: What the long run shows. World Bank Economic Review 2: 1-47.

Guerra EA, Bobenrieth H ESA, Bobenrieth H JRA, Cafiero C. 2015. Empirical commodity storage model: the challenge of matching data and theory. European Review of Agricultural Economics 42: $607-623$.

Gustafson RL. 1958. Carryover levels for grains: A method for determining amounts that are optimal under specified conditions. Technical Bulletin 1178, US Dept. of Agriculture.

Hamilton JD. 1994. Time Series Analysis. Princeton: Princeton University Press.

Harrell FE. 2001. Regression Modeling Strategies: With Applications to Linear Models, Logistic Regression, and Survival Analysis. New York: Springer. 
Harvey AC, Jaeger A. 1993. Detrending, stylized facts and the business cycle. Journal of Applied Econometrics 8: 231-247.

Harvey DI, Kellard NM, Madsen JB, Wohar ME. 2010. The Prebisch-Singer hypothesis: Four centuries of evidence. The Review of Economics and Statistics 92: 367-377.

Kellard NM, Wohar ME. 2006. On the prevalence of trends in primary commodity prices. Journal of Development Economics 79: 146-167.

Michaelides A, Ng S. 2000. Estimating the rational expectations model of speculative storage: A Monte Carlo comparison of three simulation estimators. Journal of Econometrics 96: 231-266.

Miranda MJ, Rui X. 1999. An empirical reassessment of the commodity storage model. Mimeo, The Ohio State University.

Nocedal J, Wright SJ. 2006. Numerical Optimization. New York: Springer.

Pfaffenzeller S, Newbold P, Rayner A. 2007. A short note on updating the Grilli and Yang commodity price index. World Bank Economic Review 21: 151-163.

Prebisch R. 1950. The economic development of Latin America and its principal problems. New York: United Nations.

Rios LM, Sahinidis NV. 2013. Derivative-free optimization: a review of algorithms and comparison of software implementations. Journal of Global Optimization 56: 1247-1293.

Roberts MJ, Schlenker W. 2013. Identifying supply and demand elasticities of agricultural commodities: Implications for the US ethanol mandate. The American Economic Review 103: 2265-2295.

Seale JL Jr, Regmi A. 2006. Modeling international consumption patterns. Review of Income and Wealth 52: 603-624.

Singer HW. 1950. The distribution of gains between investing and borrowing countries. The American Economic Review 40: 473-485.

Vaz AIF, Vicente LN. 2007. A particle swarm pattern search method for bound constrained global optimization. Journal of Global Optimization 39: 197-219.

World Bank, FAO. 2012. The Grain Chain: Food Security and Managing Wheat Imports in Arab Countries. Washington, DC: World Bank.

Yamada H, Yoon G. 2014. When Grilli and Yang meet Prebisch and Singer: Piecewise linear trends in primary commodity prices. Journal of International Money and Finance 42: 193-207.

Zeng D. 2012. Out of sight, out of mind? Estimating commodity price dynamics using detrended price. Mimeo, UC Berkeley. 